\title{
Population-based study of the prevalence of family history of cancer: Implications for cancer screening and prevention
}

Scott D. Ramsey, MD, PhD ${ }^{1,2}$, Paula Yoon, ScD, $M P H^{3}$, Ramal Moonesinghe, $P h D^{3}$, and Muin J. Khoury, MD, PhD

\begin{abstract}
Purpose: Family history assessment is gaining importance as a potential public health tool to help determine susceptibility to common cancers. Population-based data on the prevalence of having a family history of common cancers are scant. Methods: We queried survey questions from the National Health Interview Survey, an annual nationwide survey of approximately 36,000 households in the United States, to determine the prevalence of persons reporting one or more first-degree relatives with breast, colorectal, lung, prostate, or ovarian cancer. Results: Breast cancer was the most common condition noted for family members ( $7.74 \%$ of respondents), followed by lung cancer (7.10\%), colorectal cancer (4.96\%), prostate cancer (4.68\%), and ovarian cancer (1.79\%). A family history of cancer was more commonly reported by older persons, whites, women, and high-income groups. Conclusion: A substantial proportion of persons in the United States report having a close family member with cancer, and thus may be eligible for earlier or more aggressive cancer screening services. Genet Med 2006:
\end{abstract} 8(9):571-575.

Family health history assessment is a potentially valuable tool for reducing the societal burden of cancer. Individuals who have one or more first-degree relatives with cancer are often at increased risk for developing cancer, reflecting the interaction of multiple genetic variants that are more prevalent among relatives and shared environmental exposures that are as yet poorly characterized. Accordingly, several clinical practice guidelines suggest that persons meeting family history criteria for specific cancers may benefit from particular screening programs or initiating screening at an earlier age compared with people in the general population $^{1-6}$ (Table 1). In addition to screening, other clinical preventive services may be more strongly conditioned by family history, such as recommended BRCA gene mutation testing or breast cancer chemoprevention. ${ }^{7-9}$ Although a rationale exists for assessing family history, family histories are not always taken in clinical settings, nor is there a uniform method of assessment.

The clinical and economic implications of promoting population-wide family history assessment are great: Tens of millions of adults would be eligible for evaluation, and many would be told that they meet criteria for aggressive screening or prevention programs. Implementing such programs could substantially impact primary care physicians, specialists, and

\footnotetext{
From the ${ }^{1}$ Fred Hutchinson Cancer Research Center, Seattle, Washington; ${ }^{2}$ University of Washington, Seattle, Washington; ${ }^{3}$ Office of Genomics and Disease Prevention, Centers for Disease Control and Prevention, Atlanta, Georgia.

Scott D. Ramsey, Fred Hutchinson Cancer Research Center, 1100 Fairview Avenue North, M2-B230, PO Box 19024, Seattle, WA 98109.

Submitted for publication March 14, 2006.

Accepted for publication July 5, 2006.
}

DOI: 10.1097/01.gim.0000237867.34011.12 public and private health care payers. Thus, it is important to determine the likely yield from population-wide family history assessment, because it will influence both the clinical impact and the cost-effectiveness of screening and prevention programs. Accordingly, we sought to estimate the prevalence in the general population of having family histories that may connote an increased risk for colorectal, lung, breast, ovarian, or prostate cancers.

\section{MATERIALS AND METHODS}

\section{Study population and survey instrument}

Our sample population was participants in the $2000 \mathrm{Na}$ tional Health Interview Survey (NHIS), a national cross-sectional interview survey of approximately 36,000 U.S. households. This survey is conducted annually by the National Center for Health Statistics (NCHS) ${ }^{10}$ and serves as a principal source of information on the health of the civilian, noninstitutionalized U.S. population. For the 2000 NHIS, the National Cancer Institute and the Centers for Disease Control's National Center for Chronic Disease Prevention and Health Promotion provided funding to include a Cancer Control Module covering genetic testing and family history of cancer. Respondents were asked whether biologic parents, siblings, or children ever had cancer and, if so, what kind of cancer they had. Our family history data were based on responses to this survey.

\section{Analysis}

In the prevalence calculations, if at least one of the family members had a particular kind of cancer, that respondent was 
Table 1

Statements on cancer family history and screening from leading organizations

\begin{tabular}{|c|c|}
\hline Cancer & Definition of increased familial risk and recommendation \\
\hline \multirow[t]{3}{*}{ Colorectal } & $\begin{array}{l}\text { USPSTF: In persons at higher risk (e.g., those with a first-degre } \\
\text { relative who receives a diagnosis of colorectal cancer before } \\
60 \text { years of age), initiating screening at an earlier age is } \\
\text { reasonable. }\end{array}$ \\
\hline & $\begin{array}{l}\text { ACS: Screening beginning at age } 40 \text { years, or } 10 \text { years before the } \\
\text { youngest case in the immediate family, whichever is earlier. }\end{array}$ \\
\hline & $\begin{array}{l}\text { U.S. Multisociety Task Force on Colorectal Cancer: Screening } \\
\text { beginning at age } 40 \text { years, or } 10 \text { years younger than the } \\
\text { youngest diagnosis in the family, whichever comes first, } \\
\text { colonoscopy every 3-5 years. }\end{array}$ \\
\hline
\end{tabular}

Breast USPSTF: Women who are at increased risk for breast cancer (e.g., those with a family history of breast cancer in a mother or sister, a previous breast biopsy revealing atypical hyperplasia, or first childbirth after age 30 years) are more likely to benefit from regular mammography than women at lower risk. The recommendation for women to begin routine screening in their 40 s is strengthened by a family history of breast cancer having been diagnosed before menopause.

NCCN: Annual screening mammography starting 10 years earlier than the earliest age of family member's breast cancer onset, but no earlier than age 25 years; or 8-10 years after chest radiation exposure, but no earlier than age 25 years; otherwise, begin screening at age 35 years.

ACS: Women at increased risk may benefit from starting mammograms when they are younger, having additional tests (e.g., breast ultrasound or MRI), or having more frequent examinations.

Ovarian ACS: Women with a high risk of developing epithelial ovarian cancer, such as those with a strong family history of this disease, may be screened with transvaginal sonography and the CA- 125 blood test. However, these tests have not been shown to lower the number of deaths caused by ovarian cancer.

Lung USPSTF: The benefit of screening for lung cancer has not been established in any group, including asymptomatic high-risk populations such as older smokers.

Prostate USPSTF: If early detection improves health outcomes, the population most likely to benefit from screening will be men aged 50 to 70 years who are at average risk, and men older than 45 years who are at increased risk (African American men and men with a family history of a first-degree relative with prostate cancer).

USPSTF, United States Preventive Services Task Force; ACS, American Cancer Society; NCCN, National Comprehensive Cancer Network; MRI, magnetic resonance imaging. considered to have a family history of that kind of cancer. All the estimates were statistically weighted to reflect national population totals. Because the NHIS is based on a stratified cluster sample design, standard errors used in computing prevalence estimates were calculated using the procedure SURVEYFREQ in SAS software, version 9 (SAS, Cary, NC). ${ }^{11}$

\section{RESULTS}

Approximately 27,000 respondents provided family history information. Table 2 lists reported prevalence of family history and associated 95\% confidence intervals for lung, colorectal, breast, ovarian, and prostate cancer by respondent age. Across all age groups, prevalence is highest for family history of breast cancer and lowest for family history of ovarian cancer. As expected, the prevalence of family history of cancer generally increases with the age of the respondent, reflecting the increased time available for family members to develop cancer. Across the age groups, the prevalence of family history of lung and colorectal cancer peaks for persons 60 to 69 years of age. Family history of breast cancer prevalence uniformly increases with each higher age group, whereas family history of ovarian cancer prevalence seems to stabilize for those 60 to 79 years of age. When the youngest and oldest age groups are compared, breast cancer shows the greatest absolute change in family history prevalence $(11.65 \%)$.

The prevalence of having a family history of cancer was higher for whites than blacks across all ages (Table 3). Stratified by sex, family history of cancer was generally higher for women than men, although in the 60 to 69 -year age group more men reported family histories of breast and colorectal cancer (Table 4).

Stratified by income group, family history of cancer was more commonly reported by those reporting the highest income (Table 5). The most notable differences between lowest and highest income groups were for histories of breast and prostate cancer. Among respondents who report at least one relative with cancer, the proportion of persons reporting more than one relative with the cancer of interest ranged from 5.1\% (ovarian cancer) to $8.2 \%$ (breast cancer) (Table 6). The number of first-degree relatives affected by cancer increased with the age of the respondent, but the majority of respondents who reported a family history had only one affected relative.

Table 2

Reported prevalence of family history of lung, colorectal, breast, and ovarian cancer and the corresponding 95\% confidence intervals

\begin{tabular}{lcccr}
\hline Age group & Lung & Colorectal & Breast & Ovarian \\
\hline $20-29 \mathrm{y}$ & $1.601 .17-2.04$ & $0.700 .46-0.94$ & $2.782 .22-3.34$ & $1.270 .89-1.65$ \\
$30-39 \mathrm{y}$ & $4.984 .32-5.65$ & $2.572 .11-3.03$ & $4.574 .02-5.12$ & $1.331 .01-1.65$ \\
$40-49 \mathrm{y}$ & $7.767 .03-8.49$ & $5.434 .73-6.13$ & $7.977 .15-8.80$ & $2.001 .58-2.42$ \\
$50-59 \mathrm{y}$ & $10.879 .84-11.90$ & $6.915 .99-7.83$ & $10.439 .38-11.49$ & $2.211 .84-2.59$ \\
$60-69 \mathrm{y}$ & $11.2610 .01-12.51$ & $10.008 .76-11.24$ & $13.5412 .19-14.90$ & $2.271 .70-2.84$ \\
$70-79 \mathrm{y}$ & $11.169 .90-12.41$ & $9.798 .55-11.03$ & $14.4312 .88-15.98$ & $2.271 .63-2.92$ \\
Total & $7.106 .75-7.44$ & $4.964 .65-5.27$ & $7.747 .34-8.13$ & $1.791 .60-1.97$ \\
\hline
\end{tabular}


Table 3

Estimates of prevalence of family history of lung, colorectal, breast, ovarian, and prostate cancer, by age group and race

\begin{tabular}{|c|c|c|c|c|c|c|c|}
\hline Age group & Race & Lung & Colorectal & Breast & Ovarian & Prostate & Total \\
\hline \multirow[t]{3}{*}{$20-29$ y } & White & 1.75 & 0.77 & 2.88 & 1.62 & 1.04 & 7.48 \\
\hline & Black & 1.65 & 0.57 & 3.30 & 0.18 & 0.55 & 6.13 \\
\hline & Other & 0.46 & 0.34 & 1.36 & 0.11 & 0.58 & 2.85 \\
\hline \multirow[t]{3}{*}{$30-39 y$} & White & 5.50 & 2.69 & 4.88 & 1.42 & 3.03 & 15.98 \\
\hline & Black & 3.84 & 3.04 & 4.45 & 0.50 & 2.43 & 12.58 \\
\hline & Other & 1.75 & 0.64 & 1.69 & 1.77 & 1.90 & 7.03 \\
\hline \multirow[t]{3}{*}{$40-49 y$} & White & 8.46 & 5.85 & 8.38 & 2.23 & 6.47 & 27.37 \\
\hline & Black & 5.14 & 4.18 & 6.73 & 0.71 & 4.40 & 18.82 \\
\hline & Other & 3.70 & 2.44 & 5.15 & 1.24 & 3.80 & 15.39 \\
\hline \multirow[t]{3}{*}{$50-59$ y } & White & 11.52 & 7.28 & 10.95 & 2.29 & 6.86 & 32.57 \\
\hline & Black & 8.98 & 4.32 & 9.11 & 1.88 & 6.05 & 26.76 \\
\hline & Other & 3.94 & 5.63 & 4.58 & 0.97 & 1.34 & 15.13 \\
\hline \multirow[t]{3}{*}{$60-69 y$} & White & 12.38 & 10.03 & 14.07 & 2.52 & 7.00 & 36.36 \\
\hline & Black & 4.53 & 10.97 & 11.03 & 0.0 & 9.97 & 30.86 \\
\hline & Other & 2.56 & 7.66 & 8.23 & 1.88 & 0.59 & 20.00 \\
\hline \multirow[t]{3}{*}{$70-79 y$} & White & 11.51 & 10.27 & 14.99 & 2.30 & 8.07 & 37.62 \\
\hline & Black & 9.13 & 4.67 & 9.72 & 2.03 & 10.19 & 30.00 \\
\hline & Other & 6.39 & 9.13 & 10.55 & 2.16 & 3.33 & 28.27 \\
\hline \multirow[t]{3}{*}{ Total } & White & 7.83 & 5.36 & 8.30 & 1.99 & 5.00 & 24.13 \\
\hline & Black & 4.70 & 3.64 & 6.19 & 0.72 & 4.01 & 16.97 \\
\hline & Other & 2.35 & 2.40 & 3.55 & 1.11 & 1.97 & 10.52 \\
\hline
\end{tabular}

Table 4

Estimates of prevalence of family history of lung, colorectal, breast, ovarian, and prostate cancer, by age group and sex

\begin{tabular}{|c|c|c|c|c|c|c|c|}
\hline Age group & Sex & Lung & Colorectal & Breast & Ovarian & Prostate & Total \\
\hline \multirow[t]{2}{*}{$20-29 y$} & M & 1.39 & 0.45 & 2.87 & 0.70 & 0.67 & 5.74 \\
\hline & $\mathrm{F}$ & 1.81 & 0.95 & 2.70 & 1.83 & 1.18 & 7.90 \\
\hline \multirow[t]{2}{*}{$30-39 y$} & $\mathrm{M}$ & 4.69 & 2.49 & 3.85 & 1.10 & 3.06 & 13.85 \\
\hline & $\mathrm{F}$ & 5.26 & 2.65 & 5.25 & 1.54 & 2.67 & 15.75 \\
\hline \multirow[t]{2}{*}{$40-49 y$} & M & 7.50 & 4.56 & 7.24 & 2.01 & 6.39 & 24.49 \\
\hline & $\mathrm{F}$ & 8.03 & 6.30 & 8.71 & 1.99 & 5.71 & 26.70 \\
\hline \multirow[t]{2}{*}{$50-59$ y } & M & 10.62 & 6.45 & 9.17 & 1.96 & 6.70 & 29.68 \\
\hline & $\mathrm{F}$ & 10.70 & 7.34 & 11.64 & 2.39 & 6.29 & 32.41 \\
\hline \multirow[t]{2}{*}{$60-69 y$} & M & 10.70 & 10.48 & 14.06 & 2.23 & 7.01 & 35.99 \\
\hline & $\mathrm{F}$ & 11.74 & 9.59 & 13.11 & 2.31 & 7.05 & 34.43 \\
\hline \multirow[t]{2}{*}{$70-79 y$} & $\mathrm{M}$ & 9.99 & 9.28 & 13.08 & 1.75 & 8.28 & 34.82 \\
\hline & $\mathrm{F}$ & 12.09 & 10.19 & 15.51 & 2.69 & 7.93 & 38.22 \\
\hline \multirow[t]{2}{*}{ Total } & M & 6.67 & 4.54 & 7.06 & 1.54 & 4.77 & 21.18 \\
\hline & $\mathrm{F}$ & 7.50 & 5.35 & 8.37 & 2.02 & 4.61 & 23.51 \\
\hline
\end{tabular}

The questionnaire does not record the age of the relative at diagnosis.

\section{DISCUSSION}

Family history assessment is gaining importance as a research tool, a clinical marker of increased risk for disease, and a potential tool for initiating aggressive cancer screening and prevention. ${ }^{12-14}$ The NHIS has the advantage of national sampling that is designed to represent the composition of the U.S. population. We report here the prevalence of family histories for cancers that are commonly reported during family history interviews. Overall, approximately one in four study participants reports that a close relative has had cancer. Those reporting "positive" family histories are more common among older persons, women, whites, and higher income groups.

Because NHIS uses a well-established approach to population sampling, our data may be the most accurate representation of reported family cancer history in the United States. Most reports of family cancer history are based on convenience samples 
Table 5

Estimates of prevalence of family history of lung, colorectal, breast, ovarian, and prostate cancer, by age group and ratio of family income to poverty threshold

\begin{tabular}{|c|c|c|c|c|c|c|c|}
\hline Age group & Income & Lung & Colorectal & Breast & Ovarian & Prostate & Total \\
\hline \multirow[t]{4}{*}{$20-29$ y } & $1^{a}$ & 1.41 & 0.59 & 1.98 & 0.84 & 1.06 & 5.48 \\
\hline & $2^{b}$ & 1.49 & 0.86 & 2.91 & 1.45 & 0.74 & 7.12 \\
\hline & $3^{c}$ & 1.58 & 0.83 & 2.58 & 1.12 & 1.00 & 6.75 \\
\hline & $4^{d}$ & 0.65 & 0.77 & 3.61 & 1.64 & 1.36 & 7.63 \\
\hline \multirow[t]{4}{*}{$30-39$ y } & 1 & 4.74 & 1.51 & 3.05 & 1.67 & 1.61 & 12.02 \\
\hline & 2 & 5.11 & 2.11 & 4.72 & 1.84 & 2.66 & 14.48 \\
\hline & 3 & 5.45 & 2.59 & 5.47 & 1.32 & 3.12 & 16.71 \\
\hline & 4 & 4.83 & 3.33 & 5.12 & 0.83 & 3.91 & 16.48 \\
\hline \multirow[t]{4}{*}{$40-49$ y } & 1 & 8.80 & 4.34 & 4.60 & 2.75 & 4.01 & 21.08 \\
\hline & 2 & 8.10 & 4.45 & 7.18 & 2.19 & 5.73 & 23.90 \\
\hline & 3 & 7.22 & 6.91 & 8.38 & 1.79 & 7.01 & 27.65 \\
\hline & 4 & 7.75 & 5.92 & 8.57 & 1.61 & 6.36 & 26.47 \\
\hline \multirow[t]{4}{*}{$50-59$ y } & 1 & 9.54 & 6.14 & 8.12 & 1.66 & 3.07 & 24.50 \\
\hline & 2 & 11.09 & 6.00 & 8.70 & 1.83 & 4.87 & 28.77 \\
\hline & 3 & 11.42 & 4.09 & 12.11 & 2.10 & 6.64 & 30.30 \\
\hline & 4 & 11.35 & 8.98 & 11.31 & 2.50 & 7.62 & 35.17 \\
\hline \multirow[t]{4}{*}{$60-69$ y } & 1 & 9.95 & 12.51 & 11.06 & 0.81 & 6.36 & 32.65 \\
\hline & 2 & 11.48 & 10.72 & 12.64 & 1.85 & 6.89 & 33.38 \\
\hline & 3 & 10.14 & 12.57 & 15.11 & 3.91 & 8.40 & 41.23 \\
\hline & 4 & 10.72 & 8.86 & 16.29 & 1.92 & 7.67 & 35.36 \\
\hline \multirow[t]{4}{*}{ 70-79y } & 1 & 12.21 & 5.55 & 8.95 & 1.66 & 5.03 & 25.37 \\
\hline & 2 & 11.92 & 11.38 & 16.52 & 2.51 & 8.58 & 40.31 \\
\hline & 3 & 11.26 & 11.18 & 17.86 & 3.35 & 10.73 & 42.26 \\
\hline & 4 & 10.56 & 9.41 & 17.13 & 2.77 & 7.89 & 38.94 \\
\hline \multirow[t]{4}{*}{ Total } & 1 & 5.99 & 3.55 & 4.87 & 1.49 & 2.74 & 15.85 \\
\hline & 2 & 6.85 & 4.72 & 7.34 & 1.90 & 4.21 & 21.05 \\
\hline & 3 & 6.63 & 4.86 & 8.08 & 1.84 & 4.94 & 22.64 \\
\hline & 4 & 7.28 & 5.79 & 8.69 & 1.69 & 5.49 & 24.75 \\
\hline
\end{tabular}

${ }^{a} 1=<0.99$.

$b_{2}=1.00-2.99$.

$c_{3}=3.00-4.99$.

$d_{4}=>5.00$

Table 6

Proportion of respondents reporting at least one relative with cancer who report one, two, or three or more first-degree relatives with cancer

\begin{tabular}{lccc}
\hline Cancer & FDR $=1$ & FDR $=2$ & FDR $\geq 3$ \\
\hline Colorectal & $93.13 \%$ & $5.03 \%$ & $1.84 \%$ \\
Ovarian & $94.87 \%$ & $4.51 \%$ & $0.62 \%$ \\
Breast & $91.78 \%$ & $7.22 \%$ & $1.00 \%$ \\
Lung & $93.56 \%$ & $5.20 \%$ & $1.24 \%$ \\
Prostate & $93.49 \%$ & $5.48 \%$ & $1.03 \%$ \\
\hline
\end{tabular}

FDR, first-degree relative. or cancer-specific registries built for research purposes and therefore do not approximate population sampling, as the NHIS does.

These data may prove useful to those interested in research applications that are in part determined by the prevalence of family history of cancer, such as applications that estimate the cost-effectiveness of cancer risk-assessment programs. If more intensive screening is to be an actionable outcome of family cancer history assessment, this analysis may also help predict the likely burden of screening on physicians, clinics, medical systems, and health insurers.

The NHIS questionnaire has certain limitations: it does not record the age of the relative at diagnosis or ask the respondent 
to list the cancer within the relative with site-specific prompting as to cancer type. In addition, family history reporting is subject to bias, influenced by respondent's recollection, discussions among family members (or lack thereof), and ability to accurately identify particular cancers. By using cancer registry data as a gold standard, some researchers have found high reliability of probands' reporting of first-degree relatives' cancers on most cancer sites. ${ }^{15}$ Nevertheless, some of our findings suggest that reporting bias is possible. For example, we find a lower prevalence of prostate cancer family history in blacks compared with whites, yet the National Cancer Institute's Surveillance, Epidemiology, and End Results cancer registry reports a higher prevalence of this cancer in blacks. ${ }^{16}$ The finding of higher prevalences of cancer family history among higher income persons may reflect educational attainment and corresponding "awareness of the need" to know family history rather than true differences in prevalence by income group. In addition, persons with higher income and white race have higher rates of screening, which in turn may influence the prevalence of certain cancers with long latency periods (e.g., prostate). These and other data suggest that certain demographic factors are associated with reporting of family health history. ${ }^{17}$ If family cancer history is to be a useful screening tool, certain subgroups of the population might benefit from targeted programs to raise awareness about the importance of knowing family health history. The Centers for Disease Control has begun an initiative to encourage individuals to know their family history and bring this information to the attention of their health care providers. ${ }^{18,19}$

Cancer screening and prevention guidelines have varying definitions of what constitutes a "high-risk" family history. Some suggest that those with first-degree relatives who develop cancer at a young age and those with multiple affected relatives are at high enough risk to warrant early screening (Table 1 ). The NHIS does not provide information on the age at onset of relatives with cancer, although it is possible to identify persons who have more than one affected family member. Looking at combinations of cancers in families will be useful for some rarer genetic syndromes. If the definition of a high-risk family cancer history can be standardized, future NHIS surveys may be able to ask questions in a way that estimates the prevalence of persons meeting such criteria. It has been noted that family history taking in clinical settings is inconsistent and may not be keeping pace with changes in knowledge of cancer genetics. ${ }^{20-22}$ Future areas for research also include translation of questions such as those contained in the NHIS into formats that can be easily administered in practice settings.

\section{ACKNOWLEDGMENTS}

Funding provided by National Cancer Institute (R01 HG002941), National Human Genome Research Institute (R01 HG02263), and Centers for Disease Control and Prevention.

\section{References}

1. US Preventive Services Task Force. Guide to clinical preventive services. Cancer screening. Available at: http://www.ahrq.gov/clinic/cps3dix.htm\#cancer. Accessed March 9, 2006

2. National Center for Chronic Disease Prevention and Health Promotion. Centers for Disease Control and Prevention, Division of Cancer Prevention and Control. Available at: http://www.cdc.gov/cancer/index/htm. Accessed March 9, 2006.

3. Winawer S, Fletcher R, Rex D, Bond J, et al. Colorectal cancer screening and surveillance: clinical guidelines and rationale-update based on new evidence. Gastroenterology 2003;124:544-560.

4. National Cancer Institute. Screening and testing to detect cancer. Available at: http://www.cancer.gov/cancertopics/screening. Accessed March 9, 2006.

5. American Cancer Society. ACS cancer detection guidelines. Available at: http://www. cancer.org/docroot/PED/content/PED_2_3X_ACS_Cancer_Detection_Guidelines_ 36.asp. Accessed March 9, 2006.

6. National Comprehensive Cancer Network. Guidelines for detection, prevention, and risk reduction of cancer. Available at: http://www.nccn.org/professionals/physician_gls? f_guidelines.asp?button = I+Agree\#detection. Accessed March 9, 2006.

7. U.S. Preventive Services Task Force. Genetic risk assessment and BRCA mutation testing for breast and ovarian cancer susceptibility. Available at: http://www.ahrq. gov/clinic/uspstf/uspsbrgen.htm. Accessed January 25, 2006.

8. Chlebowski RT, Col N, Winer EP, Collyar DE, et al. American Society of Clinical Oncology technology assessment of pharmacologic interventions for breast cancer risk reduction including tamoxifen, raloxifene, and aromatase inhibition. J Clin Oncol 2002;20:3328-3343.

9. US Preventive Services Task Force. Chemoprevention of breast cancer: recommendations and rationale. July 2002. Available at: http://www.guidelines.gov/ summary/summary.aspx?doc_id $=3229 \& \mathrm{nbr}=002455 \&$ string $=$ tamoxifen\#s 23 . Accessed March 9, 2006.

10. National Center for Health Statistics. National Health Interview Survey (NHIS). Centers for Disease Control and Prevention. Available at: http://www.cdc.gov/nchs/ nhis.htm. Accessed March 9, 2006.

11. SAS Corporation. SAS ${ }^{\circledR 9}$. Cary, NC: SAS Institute, Inc.:2005.

12. Bell J. The new genetics in clinical practice. BMJ 1998;316:618-620.

13. Qureshi N, Raeburn JA. Clinical genetics meets primary care. BMJ 1993;307:816817.

14. Emery J, Hayflick S. The challenge of integrating genetic medicine into primary care. BMJ 2001;322:1027-1030.

15. Ziogas A, Anton-Culver H. Validation of family history data in cancer family registries. Am J Prev Med 2003;24:190-198.

16. National Cancer Institute. Complete and limited-duration cancer prevalence estimates, prostate cancer. In: Ries LAG, Harkins D, Krapcho M, Mariotto A, et al. (editors). SEER Cancer Statistics Review, 1975-2003. Bethesda (MD): National Cancer Institute. Available at: http://seer.cancer.gov/csr/1975_2002/. Accessed March 10, 2006

17. Centers for Disease Control and Prevention. Awareness of family health history as a risk factor for disease-United States, 2004. Morb Mortal Wkly Rep 2004;53:10441047.

18. Yoon PW, Scheuner MT, Peterson-Oehlke KL, Gwinn M, et al. Can family history be used as a tool for public health and preventive medicine? Genet Med 2002;4:304-310.

19. Scheuner MT, Yoon PW, Khoury MJ. Contribution of Mendelian disorders to common chronic disease: opportunities for recognition, intervention, and prevention. Am J Med Genet C Semin Med Genet 2004;125:50-65.

20. Grover S, Stoffel EM, Bussone L, Tschoegl E, et al. Physician assessment of family cancer history and referral for genetic evaluation in colorectal cancer patients. Clin Gastroenterol Hepatol 2004;2:813-819.

21. Schroy PC, Barrison AF, Ling BS, Wilson S, et al. Family history and colorectal cancer screening: a survey of physician knowledge and practice patterns. Am J Gastroenterol 2002;97:1031-1036.

22. Rose PW, Watson E, Yudkin P, Emery J, et al. Referral of patients with a family history of breast/ovarian cancer-GPs' knowledge and expectations. Fam Pract 2001; 18:487-490. 